\title{
Mujer, música y Transición. Una perspectiva desde el diario El País
}

Emakumea, musika eta trantsizioa. Perspektiba bat El País egunkariaren ikuspuntutik

Women, music and the Transición. A perspective from the newspaper El País

\author{
Alicia Pajón Fernández \\ Universidad de Oviedo
}

RESUMEN: En este escrito se busca indagar en los artículos relacionados con la música publicados en El País entre 1976 y 1982 la visión que se da de las artistas y la presencia de las mujeres como redactoras de información musical. Se analiza cómo el canon que esta publicación diseña en torno a la música en la Transición incluye o no a las artistas femeninas y la imagen que se proyecta de estas. Observamos, además, los perfiles de las mujeres que consiguieron hacerse hueco en la redacción, como es el caso de Mercedes Domenech, Rosa María Pereda o Bel Carrasco.

PALABRAS CLAVE: Análisis del discurso; música; prensa; representación de la mujer; Transición.

ABSTRACT: This article seeks to delve into the articles published about music by El País between 1976 and 1982 the perspective given towards female women and the women's presence as musical journalists. We will analyze how the canon designed by the publication around music in the Transición includes or not certain female artists as well as the image that the newspaper projects of them. We will also look at the profiles of those women who did made a name for themselves in the publication as critics, such as Mercedes Domenech, Rosa María Pereda or Bel Carrasco.

KEYWORDS: Discourse analysis; music; press; representation of women; Transición.

\footnotetext{
* Correspondencia a / Corresponding author: Alicia Pajón Fernández. Universidad de Oviedo. Departamento de Historia del Arte y Musicología. Universidad de Oviedo. C/ Amparo Pedregal, s/n (33011 Oviedo) - u0239870@uniovi.es - http://orcid.org/0000-0003-0191-8705

Cómo citar / How to cite: Pajón Fernández, Alicia (2019). "Mujer, música y Transición. Una perspectiva desde el diario El País»; Zer, 24(46), 253-268. (https://doi.org/10.1387/zer.20602).

Recibido: 19 febrero, 2019; Aceptado: 27 abril, 2019.

ISSN 1137-1102 - eISSN 1989-631X / (c) 2019 UPV/EHU

(c) (i) Esta obra está bajo una licencia

Creative Commons Atribución 4.0 Internacional
} 


\section{Introducción}

El diario El País aparece el día 4 de mayo de 1976, poco más de cinco meses después del fallecimiento de Francisco Franco. En ese momento, y tras 40 años de represión, el papel y la visión de la mujer en la sociedad empieza a cambiar, y los movimientos feministas afloran dejándose sentir en los medios de comunicación. Por ello, en este artículo se tratará de analizar la imagen que El País ofrece de las mujeres que se dedican a la música, así como apreciar el grado de participación de la mujer como integrante de la redacción, entre los años 1976, año de aparición del periódico y el año 1982, momento en que Felipe González llega al poder. Esta periodización se extrae de los trabajos de Javier Tusell, especialmente el libro La Transición a la democracia (España 1975-1982), aunque siempre bajo la premisa de que otras periodizaciones serían tan válidas como la aquí tomada. Por supuesto, ha de tenerse en cuenta que este estudio se hace desde una perspectiva actual, donde se ha tomado una mayor conciencia de la poca representación de la mujer en los distintos ámbitos.

Los medios de comunicación tienen un destacado papel a la hora de modelar la opinión pública y de dirigir o no la atención hacia un hecho o persona. El papel de la mujer en la sociedad, y en este caso en la escena musical, se ve inevitablemente influenciado por su representación en los medios. Por lo tanto, conocer la imagen que se da de esta en uno de los periódicos de cabecera nos ayuda a comprender la concepción de la mujer en un momento tan convulso como fue la Transición. En la década de los 70, la mujer reafirmaba su presencia en el mundo laboral y en los diferentes ámbitos públicos. Sin embargo, como señala Núria Simelio en su tesis doctoral sobre la prensa generalista durante la Transición, la representación de las mujeres en los periódicos de información general no refleja su incorporación a los espacios públicos (Simelio Solá, 2006: 613-614).

Para llevar a cabo este trabajo y estudiar la representación de la mujer en el ámbito musical en el diario El País tendremos en cuenta, principalmente, dos conceptos. El primero es el de «aniquilación simbólica» (symbolic annihilation), acuñado por George Gerbner y aplicado a los estudios de género por Gaye Tuchman (Tuchman en Rovetto, 2010a: 18), para expresar la baja representación de las mujeres, muy inferior a su presencia en el mundo laboral y cultural, en los procesos mediáticos, algo que afecta a su posición social pero también a la percepción que la mujer tiene de sí misma (Rovetto, 2010b: 45). El segundo concepto que manejaremos es el de "arquetipo viril», de Amparo Moreno Sardà. Según la autora, son lo que llama los "colectivos viriles hegemónicos» — varones adultos de clase y raza dominante - quienes se sitúan en el centro del discurso, autodefiniéndose superiores a base de definir a otros individuos como inferiores, lo que se traduce en la invisibilización y exclusión de estos grupos (Moreno Sardà, 1988: 17). De este 
modo, Moreno Sardà pone de manifiesto el androcentrismo del discurso de los medios de comunicación, algo que observaremos en el diario El País. Esto se relaciona con la teoría del control del discurso que nos ofrece T. A. van Dijk en su trabajo Discurso y poder (2009). Este autor considera que el control social llega a través del control del propio discurso y de su producción, estando este dominado por unas «élites simbólicas». Para el lingüista es importante prestar atención a quiénes son las personas que poseen el suficiente poder como para que su discurso llegue a los medios de comunicación para su reproducción (van Dijk, 2009: 64-66). Las «élites simbólicas» de van Dijk se corresponden con el «arquetipo viril» de Moreno Sardà, es decir, una clase dominante que ejerce un control a nivel discursivo y que con ello consigue modelar la opinión pública.

También es necesario tener en cuenta la perspectiva de la musicología feminista. Laura Viñuela en su artículo de 2003 «La construcción de identidades de género en la música popular» evidencia, a través de los trabajos de teóricas como Marcia Citron (1993) o Lucy Green (1997), el modo en que se percibe a la mujer música desde una perspectiva crítica. Mencionando a Citron, Viñuela pone en relieve la dicotomía a la que se enfrenta la mujer al llevar a cabo actividades en el ámbito público. Como dice la autora, «una mujer que pretenda desarrollar una actividad fuera del espacio doméstico tendrá que enfrentar las críticas que, inconscientemente o no, descalificarán su trabajo debido a las implicaciones sexuales de la asociación mujer-esfera pública» (Viñuela, 2003, 15). Citando a Green, Viñuela afirma que una mujer en el ámbito público, relacionado con la prostituta en contraposición a la virgen, verá «reforzadas las connotaciones sexuales negativas por la presencia del cuerpo femenino» (Viñuela, 2003: 15). Por su parte Nieves Hernández Romero y Ari F. Maia, siguiendo el trabajo de Viñuela y Viñuela, inciden en un aspecto fundamental para este estudio, como es que la ausencia de las mujeres en la historia de la música se debe más a una labor de invisibilización y silenciamiento que a su propia ausencia (Hernández Romero y Maia, 2013: 216). La prensa, a través de un proceso de inclusión/no inclusión y valoración de las diferentes artistas, se presenta como factor determinante a la hora de dar visibilidad a las músicas.

\section{Contexto}

El País nace con un discurso progresista, ofreciendo una imagen de renovación y apertura, que se adecuaba a los nuevos tiempos y que hace que se le termine relacionando con la izquierda moderada. Ofrece un enfoque que se posiciona abiertamente del lado de la democracia, y desde la redacción se apuesta por una sección de cultura fuerte, novedad con respecto al resto de periódicos del momento, aunque desde una postura un poco elitista, como señalan Cruz Seoane y Sueiro (2004: 240) y Héctor Fouce (2008: s.p.). Sea como fuere, desde el momento en que El País sale a la luz vive un ascenso meteórico y a finales del año 1976 su difusión supera los 
117.000 ejemplares vendidos en Madrid, llegando a doblarse en el año 1983. El periódico se dirigía a una población joven y formada, destacando entre personas de entre 25 y 44 años con estudios universitarios (Hernández Márquez, 2001: 30-36).

Era la época de la liberación sexual en España y el momento en que los movimientos feministas, acallados durante el franquismo, empezaban a surgir y señalaban la gran brecha de género que existía en el país. Las movilizaciones partieron, principalmente, de las universidades y de los barrios. En la universidad se forman diferentes organizaciones y entre ellas destaca la que se funda en 1975 bajo el nombre de Asociación Universitaria Para el Estudio de los Problemas de la $\mathrm{Mu}-$ jer (AUPEPM). Esta se extenderá a otras universidades y con sus acciones ponía en relieve la desigualdad de las mujeres explicando la situación siempre desde un planteamiento académico (Gahete, 2017: 584-585). También, el movimiento feminista crecía gracias a iniciativas como las I Jornadas para la Liberación de la $\mathrm{Mu}-$ jer, celebradas de forma semiclandestina en Madrid en 1975 o las Jornadas Catalanas de la Mujer de 1976 celebradas en la Universidad de Barcelona. Estas jornadas constituyeron un movimiento que englobaba mujeres feministas con perfiles muy diferentes entre sí y son consideradas como el acto fundacional del feminismo catalán (Nash, 2009: 73). Las reivindicaciones del feminismo español del momento incluían entre sus demandas: la supresión del delito de adulterio (que condenaba a hasta seis años de prisión a una mujer considerada adúltera), la garantía de los derechos reproductivos o la libre expresión sexual. Era, por lo tanto, un movimiento cuyo objetivo se centraba en «acabar con la sociedad patriarcal, opresora de la mujer» (Suárez, 2009: 101).

El País, como se ha mencionado, tenía discurso marcadamente progresista. Por ello, la lucha de las mujeres fue narrada por el diario que nacía. Sin embargo, esto contrasta cuando estudiamos el caso concreto de la música. La figura de la mujer pocas veces encuentra un papel protagonista, ni como música ni como narradora, y muchas veces la visión ofrecida es estereotipada y sesgada.

\section{Las mujeres en El País}

Si consideramos que los medios de comunicación son agentes que reflejan la distribución del poder y del control, observamos cómo estos medios, y en concreto la prensa escrita, refuerzan este patrón, creando un «marco de información construido por y para hombres» (Gallagher, 1981: 30). Gallagher expone la situación vivida por la mujer en la época que aquí se estudia, pero desde una perspectiva internacional, evidenciando la exclusión que vive por parte de los medios de comunicación. El mundo de la cultura y la música no fue diferente. Por lo tanto, ¿qué sitio les quedaba a las mujeres? Para tratar la representación de las mujeres en el ámbito musical en el diario El País se ha llevado a cabo un trabajo basado en el vaciado 
del periódico y el análisis de los artículos periodísticos sobre música. Se ha estudiado el tratamiento de la mujer desde dos ángulos diferentes:

a) La representación de las mujeres en los diferentes artículos publicados en los años estudiados. Trataremos de comprobar si en El País, como sucedía en otros medios de comunicación del momento, se ofrecía una visión estereotipada «que los varones dan a los varones sobre la mujer» (Molotch y Lester en Ruiz Montiel, 1988: 25) y, por lo tanto, si la información ofrecida estaba pasada por un tamiz masculino, en una especia de «tutela informativa» (Prieto Sánchez, 2018: 172).

b) Se ha estudiado la frecuencia con la que aparecen mujeres periodistas como autoras de los artículos firmados, ya que en un periódico la línea editorial está íntimamente ligada a la composición de su plantilla. En la época que analizamos, los hombres contaban con el dominio absoluto sobre las páginas de los periódicos. Por lo tanto, parece importante estudiar también la presencia de las mujeres en la redacción, saber qué tipo de artículos escribían y con qué frecuencia, para observar el grado de inclusión o exclusión que vivían.

\subsection{RePresentación de LAS MUJeRes en los artículos Periodísticos}

Para este análisis no se recogen todos y cada uno de los artículos que hablen de mujeres, sino aquellos donde una mujer tenga un peso importante como protagonista del acontecimiento o hecho que se narra. Para esta tarea se utilizó el análisis propuesto por Núria Simelio. La autora presenta como preguntas fundamentales frente un texto informativo: "quién elabora la explicación que ofrece cada periódico, sobre qué protagonistas centra su mirada, cuándo realizan qué actividades y en qué escenarios» (Simelio, 2006: 70).

El vaciado del periódico nos deja un total de 5757 artículos que tratan sobre música a lo largo de los años revisados. De todas estas referencias, solamente en 569 una o varias mujeres tienen un papel central, es decir, en un 9,95\% de las ocasiones. En el Gráfico 1 podemos observar la evolución de las referencias totales y la proporción de estas dedicadas a hombres y a mujeres. La tendencia es que cada vez haya más artículos referidos a mujeres, pero el crecimiento no es directamente proporcional al de los artículos dedicados a la música. Por ejemplo, entre los años 1979 y 1980 encontramos un importante aumento de las referencias globales, que pasan de 752 en el último año de la década de los setenta a 932 en el año 1980. Sin embargo, esta subida no se refleja en los artículos dedicados a mujeres, que descienden ligeramente (dos artículos menos en el año 1980), lo que se traduce en un 10,8\% de los artículos periodísticos dedicados a las mujeres en el año 1979 frente a un $8,5 \%$ en el 1980. Encontramos otro cambio notable entre el año 1981 y 1982, 
donde se pasa de un 8,8\% de artículos dedicados a las mujeres en el año 1981 a un $10,1 \%$ en el último año estudiado. En una mirada general, observamos cómo mientras durante el primer año estudiado las mujeres aparecían como protagonistas en un $11,8 \%$ de artículos, en el último año analizado, el 1982, representan el 10,1\%. Esto nos indica que, a pesar de los esfuerzos antes comentados de El País por poner en relieve las causas feministas y por señalar las situaciones de desigualdad, eran los hombres quienes que contaban con el protagonismo de la publicación, al menos en lo referente al ámbito musical.

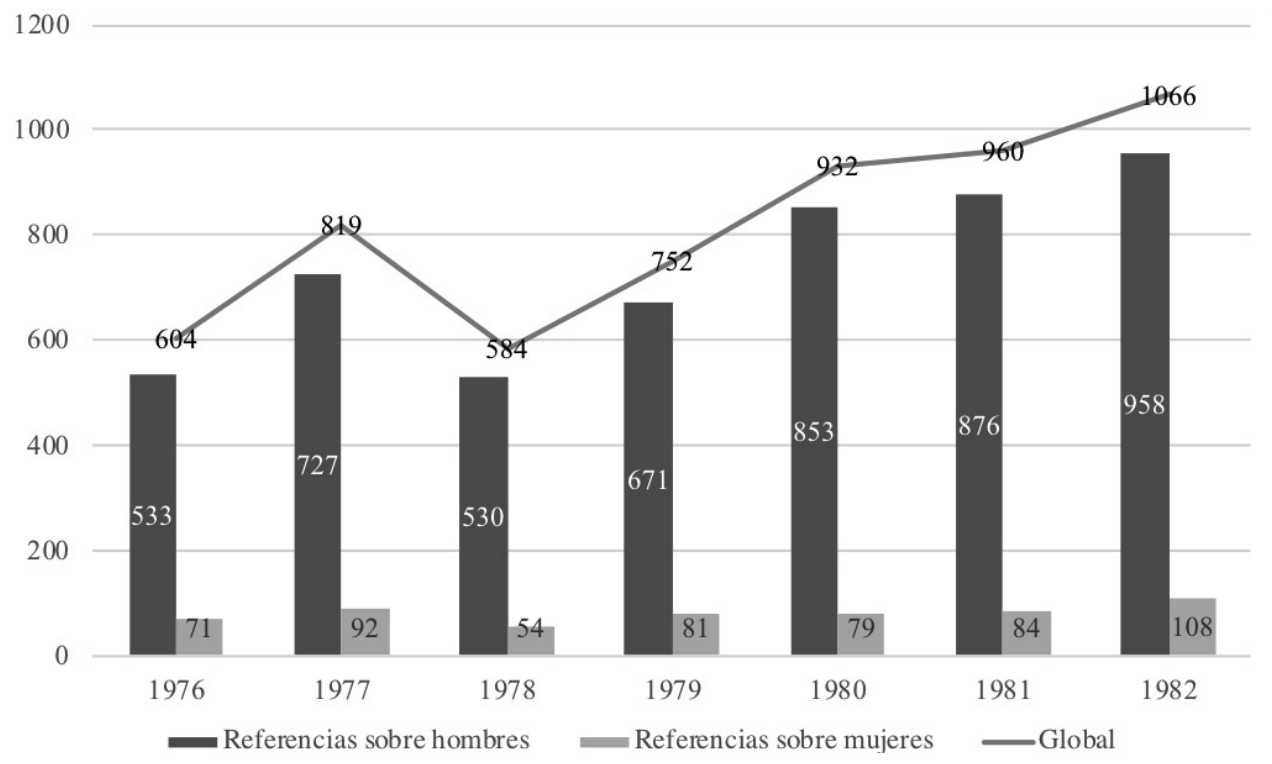

GRÁFICO 1

Son varios los artículos que merece la pena destacar. En primer lugar, hay que subrayar que El País prestaba atención a la situación de exclusión vivida por las mujeres artistas y se encargaba de señalarla. Ya en el año en que aparece el periódico, el 27 de junio, Alfonso Eduardo firmaba un artículo titulado «Las voces femeninas» (Eduardo, 1976). Allí, el autor se pregunta: «pero ¿dónde están las chicas?», poniendo énfasis en la situación de olvido que las mujeres viven en la mayor parte de los géneros musicales, pero considerando que se había producido un gran cambio gracias a los ambientes universitarios y la música que surge de estos, genéricamente designado por el autor como «estilos folk». Eduardo cita a artistas como Joni Mitchell, Laura Nyro o Janis Joplin como ejemplo de esta música. Este tema será tratado también por José Manuel Costa, el periodista que más artículos escribió sobre música popular urbana en el diario El País en los años estudiados. En el año 1977 firma un reportaje titulado «Las mujeres en el 'rock’»(Costa, 1977). De 
nuevo el autor muestra un breve repaso por la situación de la mujer en la escena musical, en este caso ciñéndose al caso del rock y poniendo en relieve cómo «desde sus principios, el rock ha sido siempre una música de hombres» (Costa, 1977).

Un artículo de la Agencia EFE, por su parte, explica la situación vivida por las mujeres compositoras, esta vez a través de una noticia del 2 de junio de 1981, donde se cubren unas jornadas musicales dedicadas a la mujer compositora en Viena. En ella se recoge el testimonio de la pianista venezolana Rosario Marciano, que señala que «algunas de las mujeres que presentamos, hoy ignoradas, fueron célebres y admiradas en su época, no hicieron piececillas ni obras pequeñas, sino incluso composiciones largas e importantes» (EFE, 1981). Parece que el diario, acorde a la tónica general de progresismo de la línea editorial, trata de visibilizar la situación de la mujer, subrayando la brecha de género existiendo y haciendo notar el hecho de que, como sentencia Costa en el reportaje citado, «los tiempos están cambiando y parece que las mujeres reclaman un puesto en la música» (Costa, 1977).

En segundo lugar, encontramos referencias explícitas al feminismo y a la ideología de las artistas, como en esta reveladora entrevista a Massiel firmada por Rosa María Pereda en el año 1976, donde la cantante afirma «lo que sí puedo decirte es que entraría en un partido feminista, en una organización que se dedicara a luchar por la emancipación de la mujer» (Pereda, 1976). Cabe señalar también una carta al director del año 1979 de parte de Marisa Vicente, militante del Colectivo Feminista de Madrid, que titula "Machismo y pseudoprogresismo en el recital de Paco Ibáñez». Testimoniando un concierto ofrecido por el músico, subraya el machismo presente en la canción "Consejos para un galán", que utiliza un texto del Arcipreste de Hita. La firmante destaca que una canción en la misma línea «referida a los «obreretes, a los negros o a los palestinos» no sería aceptada entre el público de Ibáñez ya que «ello podría dañar su reputación de "revolucionarios"» (Vicente, 1979).

Finalmente, debemos observar cómo, a pesar de un intento consciente por poner en valía la figura de la mujer, en muchas ocasiones el diario también perpetúa los comportamientos y estereotipos vigentes. Los comentarios sobre el aspecto físico de las artistas son muy habituales, y muchas veces su nombre aparece entre los titulares por noticias relacionadas con su vida familiar. Un buen ejemplo es la columna de Francisco Umbral Diario de un Snob. El día 27 de septiembre de 1977 la titula «Saritísima, divorciadísima», dedicado a Sara Montiel, y comienza su relato diciendo: «a mí no me gusta despertarme, sino que me despierten, y a ser posible que me despierte una jai ${ }^{1} »(U m b r a l, 1977)$. José Manuel Costa, que antes destacaba la ausencia

\footnotetext{
1 Según la R.A.E.: «mujer joven y atractiva», termino procedente del caló, la variedad del romaní que hablan los gitanos de España, Francia y Portugal.
} 
de las mujeres en el rock, firma una crítica en el año 1981 sobre el grupo Las Chinas (grupo formado íntegramente por mujeres) en la que dice:

ellas, con batería y todo, son un grupo de mujeres, tocando como mujeres y diciendo cosas de mujeres. Aparte del hecho estético que su presencia allí arriba supone, lo de Las Chinas como música viene cargado de una agresividad diferente de las poses de ellos (los músicos). Sus guitarreos son más blandos, pero no menos intencionados, su estar más estático, pero no menos provocador. Por así decirlo, lo de Las Chinas es música sexual, sólo que de un sexo diferente al habitual. Ese es su mérito (Costa, 1981a).

El discurso de Costa tiene un tono de alabanza, pero utiliza un lenguaje diferente al que usaría si se tratase de un grupo formado íntegramente por hombres. Las alusiones específicas a lo sexual, que nos remiten a las implicaciones sexuales de la mujer en la esfera pública que señala Viñuela; y las definiciones de la música como «blanda» y de la actuación como «estática» nos recuerdan que la música hecha por mujeres se observa como algo de inferior categoría, y que su música no siempre se toma en serio. Las menciones al fisico de las artistas también las observamos por parte de Costa en su descripción de la cantante Carrie Smith como «una negra tremenda, una señora impresionante, ataviada con un traje metalizado e imposible, gorda como una mesa camilla, pero con una capacidad para el baile muy contagiosa» (Costa, 1981b). No es la única referencia que encontramos al físico de una artista. En una noticia breve de febrero de 1977 se dice que Barbra Streisand "presume de fea porque puede»(El País, 1977a). Por último, debemos citar una crítica a un recital de Rocío Dúrcal en el Florida Park en el 1981, firmada por Luis Antonio de Villena se refiere en los siguientes términos a la letra de las canciones interpretadas por la cantante: «la paradoja del machismo azteca es que sus canciones presentan mujeres verdaderamente requebradoras y enceladas, mujeres-tío» (Villena, 1981).

Si observamos los ejemplos expuestos, podemos advertir que todos ellos están referidos a artistas relacionadas con las músicas populares urbanas. Cuando se habla de personas relacionadas con la música académica el tono cambia, se vuelve más serio y se hace referencia exclusivamente a la labor artística de la persona, siendo además estas artistas objeto de artículos de mayor extensión, como veremos a continuación.

Por ahora hemos visto cómo se habla, pero también es importante observar de quién se habla. La artista referenciada en un mayor número de ocasiones es Montserrat Caballé, a la que encontramos hasta en 39 artículos, destacando notablemente el resto de las artistas, como podemos observar en la Tabla 1. La segunda persona con un mayor número de alusiones es Lola Flores, con 19, es decir, casi la mitad que la soprano catalana. Observamos en la tabla que las artistas más refe- 
renciadas pertenecen en su mayoría al ámbito de las músicas populares. Sin embargo, cabe destacar que, mientras Montserrat Caballé, Teresa Berganza o Victoria de los Ángeles son el objetivo de críticas y crónicas, el nombre de Lola Flores, Sara Montiel y Rocío Jurado aparece principalmente como titular en las noticias breves.

TABLA 1

\begin{tabular}{|c|c|}
\hline Artista & $\mathbf{N}^{\mathbf{0}}$ de referencias \\
\hline Montserrat Caballé & 39 \\
\hline Lola Flores & 19 \\
\hline Victoria de los Ángeles & 16 \\
\hline Ana Belén & 15 \\
\hline María del Mar Bonet & 14 \\
\hline Rocío Jurado & 13 \\
\hline Teresa Berganza & 12 \\
\hline Sara Montiel & 12 \\
\hline Soledad Bravo & 10 \\
\hline Alicia de Larrocha & 9 \\
\hline Rocío Jurado & 9 \\
\hline Massiel & 9 \\
\hline
\end{tabular}

Casos diferentes son los de Ana Belén, Soledad Bravo o Massiel. Las artistas a menudo ocupan titulares por motivos alejados de su música. Ana Belén, como la mayor parte de los cantantes relacionados con el mundo de la canción de autor, ve su nombre constantemente ligado a temas extra musicales. Su relación con el Partido Comunista (Álvarez, 1982) o las distintas multas en sus recitales por considerarse estos politizados (El País, 1976a) son temas recurrentes. En el caso de Soledad Bravo, artista nacida en Logroño con nacionalidad venezolana, en el periódico se refleja cómo en el año 1976 se encontró con una notificación de expulsión del territorio español en medio de una gira por la Península (El País, 1976b); esto generó diferentes artículos, entre ellos una entrevista firmada por Moncho Alpuente (Alpuente, 1976). Massiel a su vez recibió distintas amenazas por parte de grupos armados, en una ocasión de los Comandos Guerrilleros Anticomunistas (El País, 1977b) y en otra de parte de los GRAPO (El País, 1977c), este último con un aviso de bomba en la redacción de El País. 
La forma en que aparecen las referencias que comentamos es también muy importante para entender la imagen que el periódico da de las artistas femeninas. Para llevar a cabo este análisis se dividieron las distintas referencias en nueve categorías diferentes, tomando las definiciones del Libro de estilo de El País (El País, 1996: 23-41) y de Teoría de los géneros periodísticos (Gomis, 2008: 125-203): 1. críticas, 2. gacetillas y breves, 3. noticias, 4. opinión (ensayos, tribunas de opinión y columnas), 5. entrevistas y perfiles, 6. crónicas, 7. reportajes, 8. necrológicas y 9. cartas al director. Como se puede observar en el Gráfico 2, el género en el que encontramos un mayor número de referencias a mujeres, que representan el $17,7 \%$ son las noticias breves. Sin embargo, si acudimos a géneros más extensos y con lugares más destacados dentro de las páginas del periódico como la crítica o la crónica, encontraremos que las mujeres representan solamente un $7,6 \%$ y un $5,3 \%$ respectivamente. Las mujeres tienen reservados espacios de menor relevancia, y los géneros con mayor peso entre las páginas del periódico suelen llevar titulares relacionados con artistas masculinos.

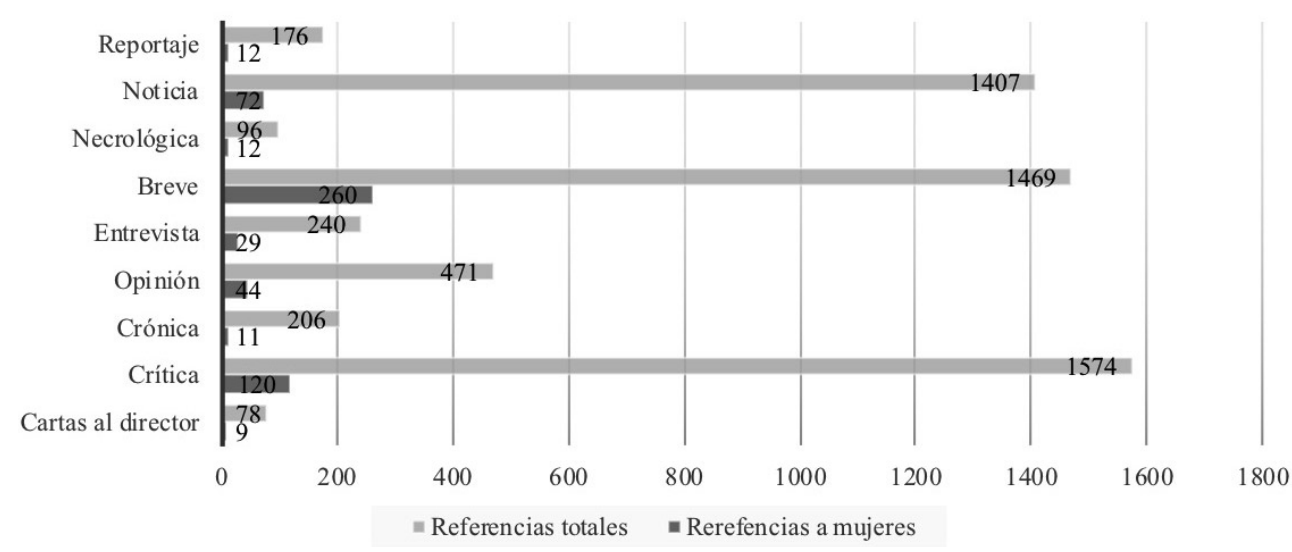

GrÁFICO 2

\subsection{LAS QUE ESCRIBÍAN}

La representación de las mujeres en El País como autoras es todavía menor que cuando observamos la frecuencia con la que las mujeres protagonizan artículos, como podemos ver en el Gráfico 3. Las mujeres firman solamente en un 3,9\% de las ocasiones, y, además, la gran mayoría de los artículos con firma femenina están dedicados a artistas masculinos. De hecho, solamente un 11,7\% de los artículos firmados por mujeres están dedicados a mujeres artistas, lo que equivale a un 4,6\% del total de artículos recogidos y estudiados. Sí cabe destacar la evolución que se experimenta en el último año estudiado, 1982, donde se aprecia un gran aumento de los artículos firmados por mujeres, representando el 8\%, superando visiblemente a los años anteriores, cuya representación ronda el 3\%. 

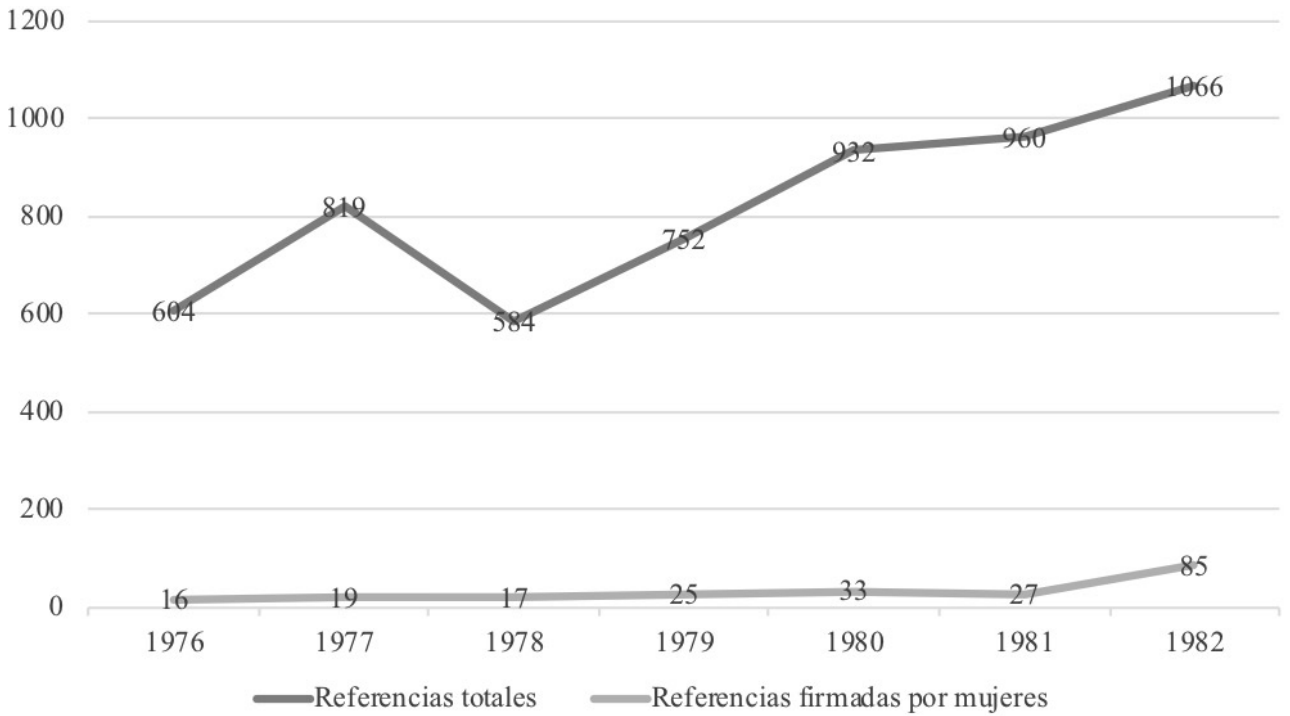

GRÁFICO 3

En la Tabla 2 podemos observar todas las mujeres que aparecen como autoras de al menos dos artículos en los años estudiados. Al analizarla, nos encontramos con el hecho de que son pocas las mujeres que escriben con asiduidad en el diario. De hecho, solamente cinco periodistas superan los diez artículos firmados y solo una de ellas, Mercedes Domenech, se encuentra en la lista de las personas que más veces firman artículos, siendo la décima en el cómputo global. Hay que tener en cuenta que esto no significa que no escribiesen más en el diario, ya que en esta tabla solamente se recogen las referencias sobre música. Un caso claro es el de Rosa Pereda, que como ella misma cuenta en su ensayo Contra Franco (1968-1978), se dedicaba principalmente a escribir sobre literatura (Pereda, 2003: 198). Hay que destacar también que muchas de las firmantes que aparecen solamente con un artículo eran firmantes de cartas al director.

Solamente cuatro periodistas superan los 20 artículos firmados. Mercedes Domenech, la redactora que encabeza la lista, es durante los años analizados la encargada de narrar la información de la música académica en la Comunidad Valenciana. Firmas críticas, crónicas y artículos de opinión, aunque su actividad en El País cesa en 1981. Sin embargo, actualmente es dificil obtener información sobre la periodista. Bel Carrasco a su vez, aunque no en exclusiva, firmaba en su mayoría entrevistas. Tras abandonar la redacción de El País en el año 1982 siguió ligada al mundo de la información, escribiendo en las páginas de cultura de El Mundo o periódicos locales como Levante o Las Provincias además de publicar novelas y libros de cuentos. De Rosa María Pereda tenemos un valioso testimonio de la época que estudiamos, 
su ya mencionado libro Contra Franco (1968-1978) (Pereda, 2003). Con un perfil polifacético, Pereda escribe tanto de música académica como sobre popular urbana, aunque especialmente de esta última, y firma géneros muy diferentes, como noticias, crónicas o entrevistas. Por último, Mercedes Rico, la cuarta periodista con más artículos firmados, ocupaba el lugar de crítica de danza.

TABLA 2

\begin{tabular}{|c|c|}
\hline Nombre & Número \\
\hline Mercedes Domenech & 33 \\
\hline Bel Carrasco & 31 \\
\hline Rosa María Pereda & 23 \\
\hline Mercedes Rico & 21 \\
\hline Rosa María Artal & 10 \\
\hline Arantza Elu & 9 \\
\hline Isabel Llorens & 6 \\
\hline María del Mar Rosell & 6 \\
\hline Esther Ferrer & 5 \\
\hline Sol Fuertes & 4 \\
\hline Ángeles Gil & 4 \\
\hline Rosa Rivas & 4 \\
\hline Soledad Álvarez Coto & 3 \\
\hline Montserrat Casals & 3 \\
\hline Lola Galán & 3 \\
\hline Genoveva Gastaminza & 3 \\
\hline Blanca Gefaell & 3 \\
\hline Elena Lorente & 3 \\
\hline Mari Carmen Raneda & 3 \\
\hline Manuela T. Mari & 3 \\
\hline Maruja Torres & 3 \\
\hline Chelo Aparicio & 2 \\
\hline Juana G. Ciero & 2 \\
\hline Soledad Gallego-Díaz & 2 \\
\hline Tonia Etxarri & 2 \\
\hline Rosa Montero & 2 \\
\hline
\end{tabular}

\section{Conclusiones}

El País, desde el momento de su creación, se presentó como un diario moderno, abierto y que apostaba por escapar del canon impuesto por el franquismo. Como se expone más arriba, el diario se encargó de narrar la causa feminista, por lo que no es extraño encontrar crónicas y noticias relatando las distintas protestas y reivindicaciones de las mujeres. Es evidente que, en sintonía con la línea editorial que se quería ofrecer, El País busca mostrar el cambio que se vivía en España y 
se suma a los nuevos tiempos. Esto lo observamos con los artículos expuestos anteriormente, que se esfuerzan por señalar la situación de marginación que la mujer vive en la industria musical. Sin embargo, todos estos artículos están firmados por un hombre. Es decir, incluso en los artículos en los que la reivindicación era evidente, esta estaba pasada por el tamiz masculino. Si recordamos el concepto "arquetipo viril» de Moreno Sardà y el de «élites simbólicas» de van Dijk observamos cómo aquí los hombres se erigen como una clase dominante, como un grupo que ostenta el control sobre el discurso y que al escoger de qué se habla (en este caso de la situación de la mujer) también están autodefiniéndose como «individuos superiores», que poseen la capacidad de influir sobre la opinión pública al contar con los canales necesarios.

A pesar de los claros esfuerzos de la publicación por visibilizar la exclusión que vivían en muchas ocasiones las artistas femeninas, no puede evitar caer en los estereotipos vigentes. El fisico de las artistas o su estado civil son temas a menudo discutidos en el periódico. Los estereotipos son especialmente visibles en la crítica que veíamos a Las Chinas, según el autor «un grupo de mujeres, tocando cosas de mujeres y diciendo cosas de mujeres». De alguna forma se tiene una actitud paternalista hacia la música que hacen las mujeres, muchas veces valorada como algo de inferior categoría o algo que queda eclipsado por el propio fisico de las artistas. Invisibilizar no es solo no hablar de las mujeres músicas, también lo es hablar de ellas prestando atención a aspectos que desde el canon androcéntrico son de menor relevancia. Así, poner el acento en el aspecto físico, en la vestimenta o en una supuesta forma de hacer música típicamente femenina no es más que continuar con unos estereotipos donde las mujeres músicas, en el mejor de los casos, están uno o varios escalones por detrás de sus colegas masculinos. En definitiva, una muestra más de la construcción varonil de esas «élites simbólicas» mencionadas por van Dijk.

Pero también la invisibilización se cristaliza en el hecho de que la información sobre mujeres aparece en espacios de menor importancia; en este sentido es relevante que el mayor número de información aparezca en las gacetillas. Esto es una muestra clara del lugar poco relevante que ocupan las músicas en la jerarquización de las noticias sobre música en esta publicación, algo que puede asociarse con el concepto de "aniquilación simbólica» definido por George Gebner. La baja representación de las mujeres artistas entre las páginas del periódico y el hecho de que sean relegadas a espacios de menor relevancia es algo que afecta, como explicaba Rovetto, no solo a la posición social de las mujeres (en este caso en el mundo musical) sino también a la propia percepción que la mujer tiene de sí misma (en este caso como artista). Claro que esta jerarquización está relacionada también con la escasa presencia de mujeres periodistas en el tratamiento de la información musical. Algo que hay que tener en cuenta para entender que, en las páginas de El País, al hablar de mujeres músicas, se ponga el acento en los cuerpos y la vida amorosa de las artistas, y se describa como una música de menor valor la realizada por mujeres. 
Teniendo en cuanta lo expuesto podemos observar la clara paradoja de El País al tratar el tema de la mujer. Por una parte, es evidente el esfuerzo por sumarse a los tiempos y a las reivindicaciones del momento, a la vez que se busca dar visibilidad a la situación vivida por las mujeres artistas. Sin embargo, por otra parte, a través de, en ocasiones, un desafortunado vocabulario y la relegación de la mujer a un segundo plano (ya sea mediante la omisión o por un tratamiento diferente al que recibe el hombre artista) el periódico contribuye a perpetuar ciertas ideas y perspectivas en torno a las mujeres que no coinciden con esa imagen de apertura que pretenden mostrar. Además, todas las menciones que se refieren de un modo u otro a la música hecha por mujeres como inferior, o señalan antes su físico que sus méritos como músicas contribuyen a la continuación de los estereotipos que alejan a las mujeres de las escenas musicales.

No podemos dejar de observar cómo los mecanismos de silenciamiento y jerarquización se activan en la publicación y contribuyen a la creación del canon que hoy conocemos de la música de la Transición. Todas las mujeres artistas omitidas por los medios de comunicación perdieron su oportunidad de llegar a la actualidad como parte de los referentes de esa época. También las valoraciones que, de una forma $\mathrm{u}$ otra, minusvaloran la música hecha por mujeres en un medio que se ubica como expresión del progresismo de su época, son una muestra palpable de las trabas que debieron enfrentar las músicas que buscaban abrirse camino en la España de aquellos años.

\section{Bibliografía}

Alpuente, M. (1976). No hay ninguna razón escrita para mi expulsión. El País, 04 de agosto [https://elpais.com/diario/1976/08/04/sociedad/207957612_850215.html] [consulta: 28/04/19].

Álvarez, J. M. (1982). Ana Belén y Víctor Manuel. El País, 20 de noviembre [https://elpais. com/diario/1982/11/20/opinion/406594804_850215.html] [consulta: 20/04/19].

Costa, J. M. (1977). Las mujeres en el «rock». El País, 19 de junio [https://elpais.com/ diario/1977/06/19/cultura/235519205_850215.html] [consulta: 15/04/19].

- (1981a). Las Chinas y la eterna diferencia. El País, 09 de mayo [https://elpais.com/ diario/1981/05/09/cultura/358207212_850215.html] [consulta: 27/04/19].

- (1981b). Monty Alexander y Carrie Smith clausuraron el festival de Vitoria. El País, 24 de julio [https://elpais.com/diario/1981/07/24/cultura/364773611_850215.html] [consulta: 27/04/19].

Cruz Seoane, M. y Sueiro, S. (2004). Una historia de El País y del Grupo Prisa. De una aventura incierta a una gran industria cultural. Barcelona: Plaza Janés.

Eduardo, A. (1976). Las voces femeninas. El País, 27 de junio [https://elpais.com/ diario/1976/06/27/cultura/204674410_850215.html] [consulta: 29/04/19]. 
EFE (1981). Debate en Viena sobre la situación de la mujer compositora. El País, 2 de junio [https://elpais.com/diario/1981/06/02/cultura/360280812_850215.html] [consulta: 18/04/19].

El País (1976a). Ana Belén. El País, 27 de agosto [https://elpais.com/diario/1976/08/27/sociedad/209944819_850215.html] [consulta: 27/04/19].

- (1976b). Soledad Bravo. El País, 01 de agosto [https://elpais.com/diario/1976/08/01/ sociedad/207698415_850215.html] [consulta: 29/04/19].

- (1977a). Barbra Streisand. El País, 23 de febrero [https://elpais.com/ diario/1977/02/23/sociedad/225500422_850215.html] [consulta: 26/04/19].

- (1977b). María de los Ángeles Santamaría. El País, 11 de mayo de 1977 [https://elpais. com/diario/1977/05/11/sociedad/232149615_850215.html] [consulta: 24/04/19].

- (1977c). Amenazas terroristas en el debut de Massiel. El País, 01 de julio [https:// elpais.com/diario/1977/07/01/cultura/236556005_850215.html] [consulta: 29/04/19].

- (1996). Libro de Estilo. Madrid: Ediciones El País.

Fouce, H. (2008). Emociones en lugar de soluciones. Música popular, intelectuales y cambio político en la España de la Transición. Trans-Revista transcultural de música (12).

Gahete Muñoz, S. (2017). Las luchas feministas. Las principales campañas del movimiento feminista español. Investigaciones feministas 8 (2), p. 583-601.

Gallagher, M. (1981). Unequal opportunities. France: Unesco.

Gomis, L. (2008). Teoría de los géneros periodísticos. Barcelona: UOCpress.

Hernández Márquez, B. (2001). El papel de la prensa en las etapas de transición a la democracia (el caso español) (Tesis doctoral). Universidad Complutense de Madrid.

Hernández Romero, N. y Maia, A. F. (2013). Músicas populares urbanas, relaciones de género y persistencia de prejuicios. Análisis de la comprensión de seis canciones por jóvenes españoles y brasileños. Musiker (30), 207-253.

Moreno Sardà, A. (1988). La otra "política» de Aristóteles. Cultura de masas y divulgación del arquetipo viril. Barcelona: Icaria.

Nash, M. (2009). Mujeres en Transición: Ciudadanía femenina, legitimidad feminista y la creación de una nueva cultura política. En M. Nash y G. Torres (Eds.) Feminismos en la Transición (p.71-88). Barcelona: Grup de Recerca Consolidat Multiculturalisme i Gènere Universitat de Barcelona.

Pereda, R. (1976). No soy del PSOE, pero me haría de un partido que luchara por la emancipación de la mujer. El País, 21 de julio [https://elpais.com/diario/1976/07/21/ cultura/206748005_850215.html] [consulta: 28/04/19].

- (2003). Contra Franco (1968-1978). Barcelona: Planeta.

Prieto Sánchez, C. (2018). ¿Quién hablan en las noticias? Desequilibrio de género en las fuentes informativas de la prensa de proximidad. Zer 23 (45), 161-184.

Rovetto, F. (2010a). La representación del trabajo de las mujeres en la prensa: Análisis comparativo y cualitativo de la información de actualidad (Tesis doctoral). Universidad Autónoma de Barcelona. 
- (2010b). Androcentrismo y medios de comunicación: Apuntes sobre la representación de las mujeres en la prensa de actualidad. Cuadernos de información ( $\left.n .^{\circ} 27\right), 43-52$.

Ruiz Montiel, J. (1988). [Reseña de la obra de Concha Fagoaga y Petra María Secanella aparecida en 1984, Umbral de presencia de las mujeres en la prensa española]. Revista de Sociología (30).

Simelio Solà, N. (2006). Prensa de información general durante la transición política española (19741984): Pervivencias y cambios en la representación de las relaciones sociales (Tesis doctoral). Universitat Autònoma de Barcelona.

Suárez Suárez, C. (2009). El asociacionismo feminista: el caso de Asturias. En M. Nash y G. Torres (Eds.) Feminismos en la Transición (p.89-122). Barcelona: Grup de Recerca Consolidat Multiculturalisme i Gènere Universitat de Barcelona.

Tusell, J. (2007). La transición a la democracia (España, 1975-1982). Madrid: Espasa.

Umbral, F. (1977). Saritísima, divorciadísima. El País, 27 de septiembre [https://elpais.com/ diario/1977/09/27/sociedad/244162811_850215.html] [consulta: 19/04/19].

Van Dijk, T. A. (2009). Discurso y poder. Barcelona: Gedisa Editorial.

Vicente, M. (1979). Machismo y pseudoprogresismo en el recital de Paco Ibáñez. El País, 28 de abril [https://elpais.com/diario/1979/04/28/opinion/294098408_850215.html] [consulta: 27:04/19]

Villena, L. A. (1981). Rocío Dúrcal: margaritas y tequila. El País, 17 de junio [https://elpais. com/diario/1981/06/17/cultura/361576801_850215.html] [consulta: 21/04/19]

Viñuela, L. (2003). La construcción de las identidades de género en la música popular. Dossiers feministes $\left(n .^{\circ} 7\right)$, pp. 11-32. 